\title{
Ecological well-being of water sources as a factor of an industrial city sustainable development
}

\author{
Nadezhda Khodorovskaia ${ }^{1,{ }^{*}, \text { Vladislav } \text { Yachmenev }^{1}, \text { Anna } \text { Kravtsova }^{1} \text {, Svetlana Kraineva }}{ }^{1}$, \\ and Larisa Deryabina ${ }^{1}$ \\ ${ }^{1}$ Chelyabisk State University, 129, Br. Kasirinykh str., 454001, Chelyabinsk, Russia
}

\begin{abstract}
In this article a "well-being" degree of the water supply source of a major industrial center (Chelyabinsk, Russia) is determined in compliance with criteria of the sustainable development goal 6 "Clean water and sanitation" (SDG 6). It is demonstrated that the Shershnevskoye reservoir corresponds to the main water quality indicators recommended by the SDG 6 and is the "good-quality" water body according to the national standards for maximum permissible concentrations for drinking water use during the entire period of the reservoir existence. The dynamics of $\mathrm{pH}$ level, mineralization, dissolved oxygen, nitrogen, phosphorus and heavy metals content in the water of the reservoir for the period from 1975 to 2020 was analyzed. Stable neutral-alkaline conditions in the reservoir water were revealed; a statistically significant decrease of mineralization, increase of dissolved oxygen content and a strong trend of mineral phosphorus growth are observed, which characterizes strengthening of photosynthetic processes and increase of productivity and anthropogenic eutrophication level of the water body. The risk factor for the reservoir ecological well-being is heavy metal content, especially iron, manganese and copper.
\end{abstract}

\section{Introduction}

Well-being of drinking and industrial water supply sources is a key to sustainable development of large industrial cities. Safe drinking water is one of the fundamental factors of human health and livehood. Water being a natural component also ensures stable functioning of ecosystems which increases water reserves and improves overall capacity to resist changes caused by anthropogenic and environmental factors [195716.29_Formatted_2018_background_notes_SDG_6.pdf].

Sustainable Development Goal (SDG) 6 related to clean water and sanitation is one of the UN-declared Sustainable Development Goals for the period until 2030. SDG 6 significantly expands the Millennium Development Goals on clean water and basic sanitation. SDG 6 evaluates 11 parameters that refer to freshwater in context of sustainable development. Bringing these aspects together under one goal is an important step towards solving the problem of establishing of coherent and sustainable water management in

\footnotetext{
*Corresponding author: nikhod@yandex.ru
} 
industrial regions and therefore SDG 6 is an important factor on the path towards sustainable future of industrial cities in the field of water supply[1].

To identify a "share of water bodies with good water quality" (indicator 6.3.2 for the goal "clean water and sanitation") it is proposed to use a three-level monitoring system. Monitoring is an essential part of the management process and provides fundamental data for aquatic sciences. This data also provides means to identify trends in water quality and evaluate effectiveness of recovery strategies [2].

General water quality is assessed with a help of a basic set of five surface water parameters providing information on the main water quality deterioration drivers in many parts of the world - oxygen depletion, increased nutrient content, acidification and salinization. With regard to fresh surface waters these parameters are dissolved oxygen content, electrical conductivity (mineralization), nitrogen content, phosphorus content and acidity value $(\mathrm{pH})[3]$.

Dissolved oxygen can determine a water pollution level: the higher the indicator value, the better water quality and vice versa. Water mineralization is determined by calcium, magnesium, potassium and sodium ions content, while anions are represented by carbonates, nitrates, bicarbonates, chlorides and sulfates. Mineralization is usually correlates and affects $\mathrm{pH}$ value. Water $\mathrm{pH}$ determines amount of a solute that can be dissolved in water as well as biological availability of nutrients, such as nitrogen or carbon, for aquatic organisms; and content of heavy metals, such as copper, cadmium, etc [4]. Compounds of nitrogen (nitrates, nitrites, ammonium nitrogen, total nitrogen) and phosphorus (phosphates, total phosphorus) determine processes of water bodies eutrophication and make a significant contribution to water body ecological well-being. In fresh continental water bodies phosphorus content is more of a limiting factor for hydrobionts and the nitrogen content is less of a limiting factor [5].

Sustainable Development Goal 6 on clean water and sanitation also provides additional parameters for water quality estimation which are determined by regional characteristics, in particular, heavy metals content. Heavy metals may be delivered from both natural and anthropogenic sources. Natural sources mainly include weathering of bedrock. Anthropogenic sources include industrial production, fertilizer use and wastewater discharge. These processes lead to heavy metals concentrations increase in biogeochemical cycles. The lowest heavy metal concentrations in water were in 1970-1980, and their increase was noted in 1990, 2000 and 2010 [6].

For estimation of a water body state, the "good-quality" characteristic is used, indicating that the water quality in this reservoir is not harmful for aquatic ecosystem functioning and human health according to basic parameters of water quality in reservoirs. A water body is classified as "good-quality" if its water parameters meet the established target standards in at least 80 percent of cases within a specified time period, or as "poor-quality" if these values meet the target indicators in less than 80 percent within the specified time period [https://communities.unep.org/display/sdg632/Documents+and+Materials].

According to the sustainable development concept, it is proposed to estimate water bodies state using national water quality indicators. In the Russian Federation in capacity of established target standards maximum permissible concentrations (MPC) of substances in water bodies are used in accordance with water use objectives applied for a particular water body. Water quality evaluation criteria for water bodies classified for drinkable water use are based on concentrations of substances that have direct or indirect impact on human health. For water bodies classified for fishery water use maximum permissible concentrations of substances $\left(\mathrm{MPC}_{\text {fishery }}\right)$ are adopted, which to a greater extent characterize favorable conditions for hydrobionts life. Comparison with MPC makes it possible to evaluate suitability of water for human lifehood not only at this particular time, but also in the near future [7]. 
Aquatic ecosystem well-being is the ability of the system to maintain its structure and function over time and under the influence of an external load taking into account all the above mentioned sub-components. Expansion of ecosystem monitoring including preservation of ecosystem "health" brings to the fore the need to protect and preserve water ecosystems including water sources in industrial cities. The most important signs of an aquatic ecosystem well-being are considered to be high water quality; high ecosystem stability against changes of water conditions parameters; low rate of toxic contamination, acidification, eutrophication and ability to preserve the above-mentioned features for a really unlimited time [8].

Water body stability against changes of regime parameters is understood as the ability to maintain its properties and conditions under applied external and internal loads. In this case bodies that are not able to maintain the specified properties for a certain functioning period will be vulnerable to the regime parameters changing.

Vulnerability or resilience analysis of a natural water system is not reduced to considering changes in single parameter properties. Stability analysis is obtained as a result of taking into account many properties characterized by a large set of evaluation parameters including natural physical, geographical and climatic conditions, factors that characterize water quality and eutrophication degree of the reservoir, as well as the nature and level of anthropogenic impact. The most important property of a natural system is the ability to maintain its original state or flow to another state, while maintaining internal bindings (inertia, plasticity). Stability of such systems is achieved by physical, mechanical and chemical transfer processes, dilution, sorption and migration of the substance [9].

This approach to definition of ecological well-being of the Shershnevskoe reservoir in Chelyabinsk region is used in our research [10]. A sampling from available data was made based on a basic set of five hydrochemical indicators $(\mathrm{pH}$, mineralization, dissolved oxygen, nitrogen and phosphorus content), which are the basis for the well-being or illbeing characteristics of the Shershnevskoe reservoir according to SDG 6 in compliance with the Russian MPC standards.

The objective of this research is to determine a well-being degree of the Shershnevskoe reservoir as a source of water supply for the large industrial center - the city of Chelyabinsk; and identification of hydrochemical indicators dynamics in the water of the reservoir over a longstanding period.

\section{Materials and methods}

The Shershnevskoye reservoir is a medium-size artificial water body located within the city of Chelyabinsk, Russia. Shershnevsky waterworks is located on the Miass River and put into operation in 1969. The reservoir is designed to supply industrial and domestic water to Chelyabinsk and satellite towns with a population of more than 1 million. According to the morphometric characteristics and water condition features this reservoir is a channel type water body having three pools - the upper pool, the main (middle) pool and the lower pool. The upper pool is the narrowest river part of the reservoir. The middle pool is slightly wider compared to the upper pool due to the flooded floodplain. The lower dam pool is the widest and deepest. The reservoir is shallow - about $50 \%$ of the area has a depth not more than $4 \mathrm{~m}$. The deepest part is located in the near-dam area. 
Table 1. The reservoir parameters at normal weather conditions.

\begin{tabular}{|c|c|}
\hline Parameter & Value \\
\hline Length & $18 \mathrm{~km}$ \\
\hline Max width & $4 \mathrm{~km}$ \\
\hline Average width & $1,6 \mathrm{~km}$ \\
\hline Water surface area & $39,1 \mathrm{~km}^{2}$ \\
\hline Amount of water & 176 million m \\
\hline Max depth & $14 \mathrm{~m}$ \\
\hline Average depth & $4,5 \mathrm{~m}$ \\
\hline Collecting area & $5460 \mathrm{~km}^{2}$ \\
\hline Bankline length & $90-100 \mathrm{~km}^{3}$ \\
\hline Replacement rate & 0.47 to $1.9-2.4$ \\
\hline
\end{tabular}

The Shershnevskoe reservoir has the status of a water body with first category of water use as a source of drinking water. The Miass River, on which the reservoir is built, has the status of a watercourse for fishery purpose. Along the banks of the reservoir there are collective gardens, recreational facilities and residential development. The reservoir is actively used by people and due to this it bears a high anthropogenic load.

On the river pool area of the Shershenevskoe reservoir near Sosnovka village water treatment facilities for preparation and feeding drinking water to the city water supply systems are located. The research area lies in the river pool of the reservoir and is situated near the city water treatment facilities intake and marked with a white square (fig.1).

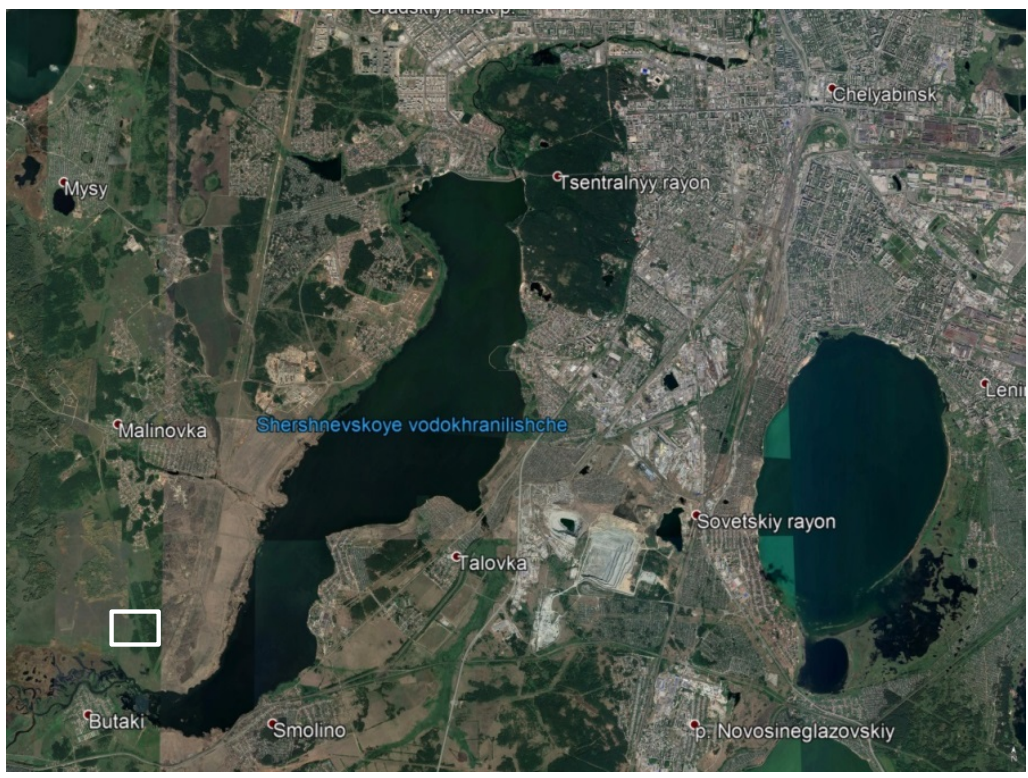

Fig. 1. Research area location in the Shershnevskoe reservoir.

Water quality studies are based on archival data from 1975 (Russian Research Institute for Integrated Water Management and Protection - South Ural branch, Chelyabinsk; Sosnovka water treatment facilities, Chelyabinsk; data from Krivopalova Z. F., Tanaeva G. V. 1981, 1983, 1985, 1989, 1990.) and proprietary materials collected in recent years $(2004$ - 2010, 2015-2020) at the Chelyabinsk State University (FSBEI of Higher Education CSU). The study analyzes growing season (May-August) from 1975 to 2020 since the ongoing biochemical processes in this period determine the reservoir ecosystem state. The research period is divided into 5-year intervals which is associated with the nature of the 
anthropogenic load.

For hydrochemical analysis $3 \mathrm{~L}$ of water were taken from the surface and depth horizons with Molchanov's bathometer. Temperature, active reaction of the medium with a portable pH meter SG2 Mettler Toledo SGo and dissolved oxygen content with a Mettler Toledo SG9 oximeter were measured directly at the observation station. Determination of all main hydrochemical water parameters was carried out in the laboratories of the Academic and Research Center for Biotechnology (Certificate of Accreditation No.ROSS RU. 0001.515711) of the Chelyabinsk State University. The indicators change analysis was obtained using regression method in a specialized Microsoft Excel program environment and Statistics Base vers. 13.5.0. For the Shershnevskoe reservoir water quality assessment for compliance to hygienic standards $\left(\mathrm{MPC}_{\text {hygienic }}\right)$ the following water parameters were analyzed: $\mathrm{pH}$, mineralization, dissolved oxygen, phosphorus, nitrogen and heavy metals content. At the same time evaluation of the reservoir ecosystem well-being was carried out using $\mathrm{MPC}_{\text {fishery }}$ standards for the same hydrochemical indicators.

\section{Results}

The $\mathrm{pH}$ numerical values in water for a longstanding period correspond to the established standard but generally reach $0.9-0.96$ of $\mathrm{MPC}_{\text {hygienic }}$ and approach the upper limit of the standard. Mineralization, dissolved oxygen, nitrates, nitrites, ammonium nitrogen, and phosphates content in the water correspond to the hygienic standards for the period from 1975 to 2020. A comparison of heavy metal concentrations values of copper, manganese and zinc demonstrated compliance with $\mathrm{MPC}_{\text {hygienic }}$; for iron average excess of $\mathrm{MPC}_{\text {hygienic }}$ by 1.2 times was observed, meanwhile the maximum excess of iron content up to 3 times was typical for the period from 2015 to 2020.

Ecosystem well-being evaluation using $\mathrm{MPC}_{\text {fishery }}$ of $\mathrm{pH}$, dissolved oxygen, mineralization, nitrate, nitrite and ammonium nitrogen showed general compliance with established standards. The phosphate content in the reservoir water also corresponds to the $\mathrm{MPC}_{\text {fishery }}$ in the period from 1975 to 2010 , but since 2015 there have been single increases over the $\mathrm{MPC}_{\text {fishery }}$ up to 1.9 times. The average multiplicity excess value of iron $\mathrm{MPC}_{\text {fishery }}$ was 1.4-3.7 times, of copper 6.4-71.5 times, of manganese 4.8-13.7 times and of zinc from 2000 to 3.8 times.

As mentioned above according to SDG 6 a water body is classified as "good-quality" if this reservoir water parameters meet the established target standards in at least 80 percent of cases within a specified time period, or as "poor-quality" if these values meet the target indicators in less than 80 percent within the specified time period. The analysis results indicated that in terms of the $\mathrm{pH}$, mineralization, dissolved oxygen, phosphorus and nitrogen content Shershenevsky reservoir water in $100 \%$ of cases is the "good-quality"

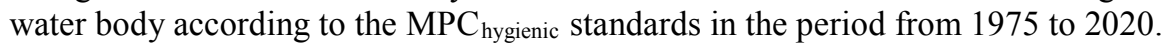

The condition of a good quality in terms of copper, zinc, and manganese content in water is met for $80 \%$ of samples. Iron content in water does not meet this criterion since 1985 (fig. 2). 


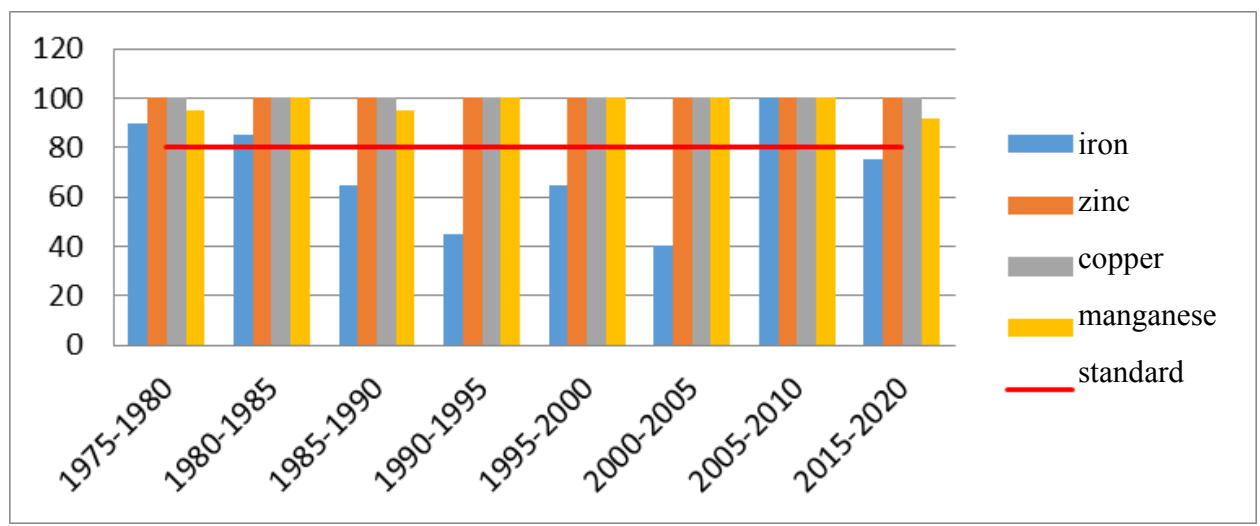

Fig. 2. Percentage of water samples corresponding to $\mathrm{MPC}_{\text {hygienic }}, \%$.

The criterion of ecological well-being of the Shershnevskoe reservoir ecosystem is fulfilled for $100 \%$ of water samples in terms of $\mathrm{pH}$, mineralization, dissolved oxygen and nitrogen content for the entire period under review. Rated phosphorus content in the period from 2015 to 2020 is observed only for $75 \%$ of the samples. When the results are compared with $\mathrm{MPC}_{\text {fishery }}$ "poor quality" of the reservoir is revealed for the entire research period in terms of heavy metal content in water, with the exception of zinc in the period from 1985 to 2000 (fig. 3).

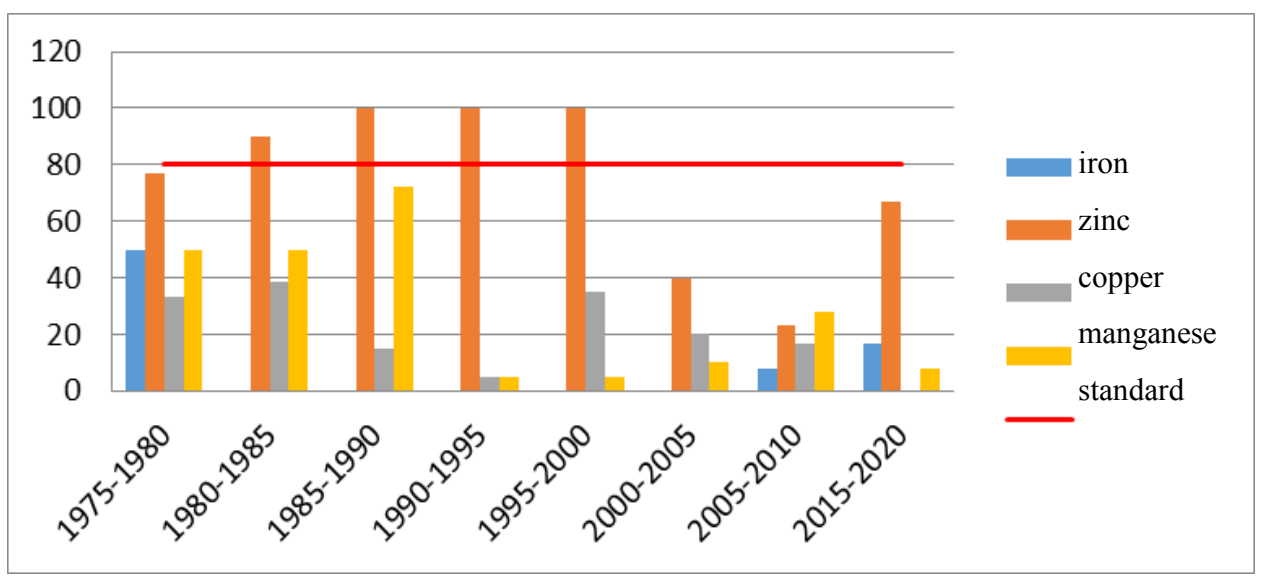

Fig. 3. Percentage of water samples corresponding to $\mathrm{MPC}_{\text {fishery }}, \%$.

Thus, it was revealed that the risk factor for the ecological well-being of the Shershnevskoe reservoir is heavy metal content, especially of iron, manganese and copper.

\section{Discussion}

Active reaction of environment has a great ecological importance for the reservoir. $\mathrm{pH}$ changes affect the survival ability of organisms, nutrition intensity, growth, gas exchange level and other biological functions.

On the fig. 4 longstanding dynamics of the hydrogen value $(\mathrm{pH})$ is represented, which indicates stable neutral-alkaline conditions in the reservoir during the growing season. The hydrogen value ranges within 7.3-8.6 from 1970 to 2009 . In the last ten years the $\mathrm{pH}$ has been gradually increasing to 8.9. Many elements, including biogenic ones, pass into an 
insoluble form in alkaline environment, while in acidic environment their solubility and consequently availability for hydrobionts increases.

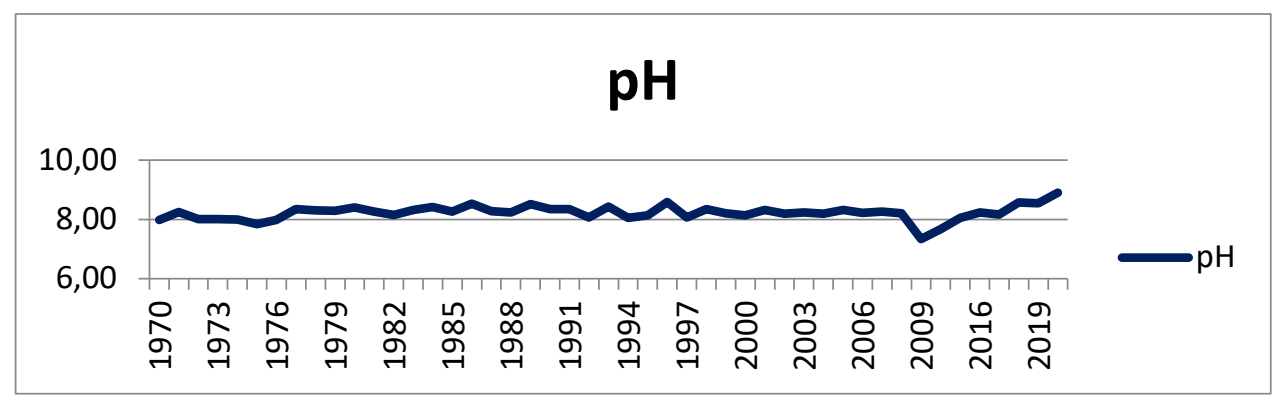

Fig. 4. pH value dynamics in the Shershnevskoe reservoir water over a long period.

In terms of chemical composition the water in the Shershnevskoe reservoir is fresh, medium-mineralized, moderately hard and corresponds to bicarbonate class of calcium group. On the fig. 5 change of water mineralization in the period from 1975 to 2020 is represented. The curve shows that there is a statistical significant decrease $(\mathrm{F}=20.8615, \mathrm{P}<$ $0.001)$ in the salt content in the water.

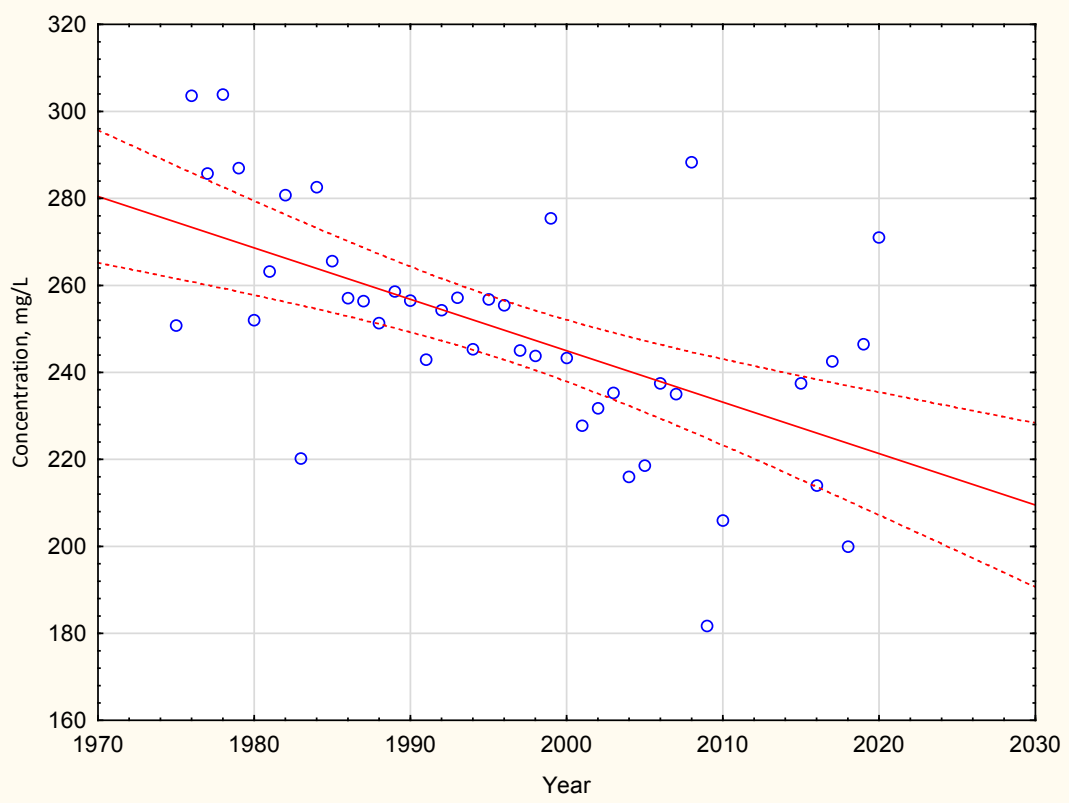

Fig. 5. Water mineralization level in the Shershnevskoe reservoir over a long period.

Dissolved oxygen content indirectly reflects the photosynthesis rate and production and destruction ratio of organic matter. The dissolved oxygen amount for the entire research period, as it can be seen on the fig. 6 , statistical significantly $(\mathrm{F}=22.87562, \mathrm{P}<0.001)$ increased from $8 \mathrm{mg} / \mathrm{L}$ to $10.4 \mathrm{mg} / \mathrm{L}$. During the growing season the phenomenon of water supersaturation with dissolved oxygen is observed in the surface layer of the reservoir within the photosynthetic zone. 


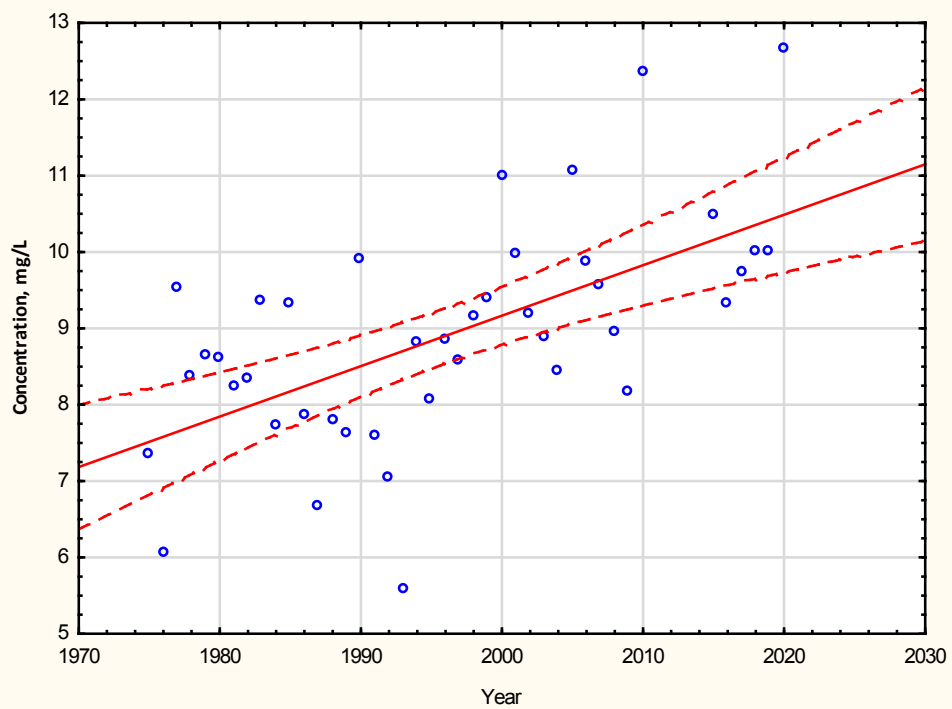

Fig. 6. Dissolved oxygen content in the Shershnevskoe reservoir water over time.

The degree of water saturation with oxygen often reaches 110.0-120.0\%, which indicates predominance of production processes in the water body. Thus, growth of dissolved oxygen concentration in water characterizes an increase in the photosynthetic processes in the water body, productivity increase and, consequently, trophicity level.

Nitrogen and phosphorus dynamics shows changes in trophic conditions of the ecosystem. Total nitrogen content in the reservoir water in the period from 1975 to 2020 ranges from 0.22 to $0.58 \mathrm{mg} / \mathrm{L}$. At the same time the maximum values of total nitrogen in water were recorded in the 1990s.

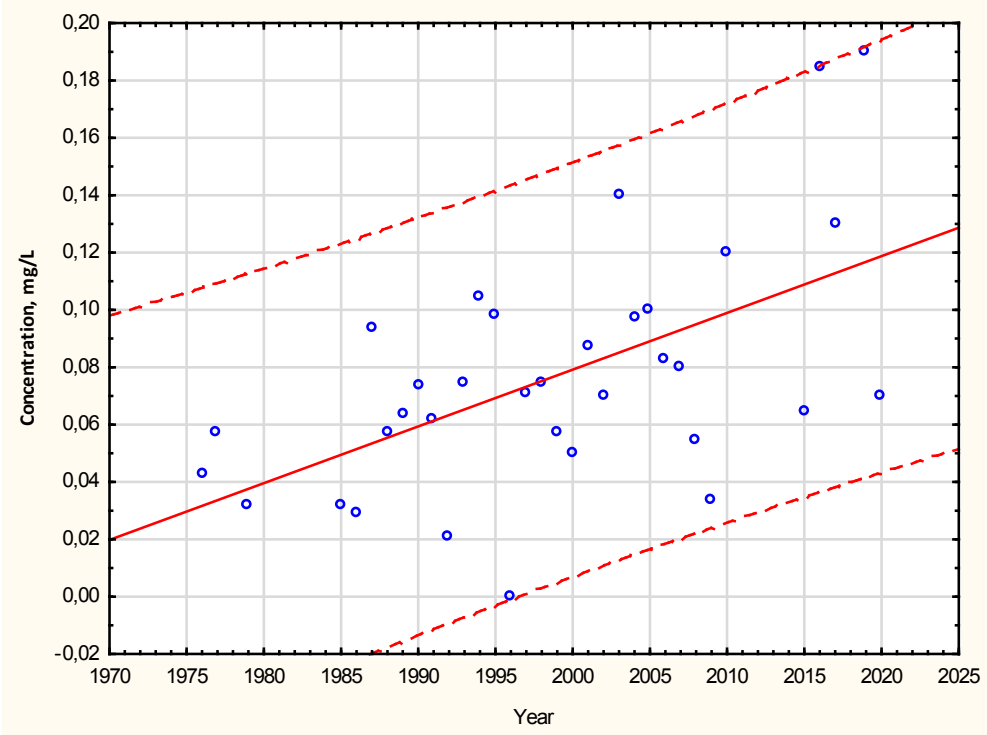

Fig. 7. Phosphates content in the Shershnevskoe reservoir water over time.

Longstanding dynamics of mineral phosphorus has a strong tendency for growth. Phosphorus concentrations increased over the entire period covered from $0.03 \mathrm{mg} / \mathrm{L}$ to 0.19 
$\mathrm{mg} / \mathrm{L}$. On the fig. 7 it is shown that a statistical significant $(\mathrm{F}=11.21842, \mathrm{P}<0.002)$ increase of phosphates concentration is observed over the whole period of the reservoir existence. Phosphates content has increased by almost $30 \%$ just in the last 20 years which is indicative of its intensive accumulation in the aquatic environment and characterizes anthropogenic eutrophication process of the reservoir.

The dominant pollutants with a toxic effect for the Shershnevskoe reservoir, which is located within the largest industrial center with developed metallurgical industry, are heavy metals. Heavy metals enter the reservoir not only from natural sources (soil, rocks), but also from surface runoff and atmospheric precipitates. Especially important is snow accumulating pollutants during winter period which duration is 4-5 months. During the winter period a large amount of suspended solids, iron, manganese and copper is accumulated in the snow cover which is significantly conditioned by washout of these pollutants from the atmosphere. Melted surface runoff carries pollutants accumulated during most of the year from collecting area and it determines composition of the reservoir waters during high water and open water. Zinc and copper are toxicants for hydrobionts, while iron and manganese in moderate amounts are biogenic elements participating in the metabolic processes of organisms and associated with trophic processes in the water body.

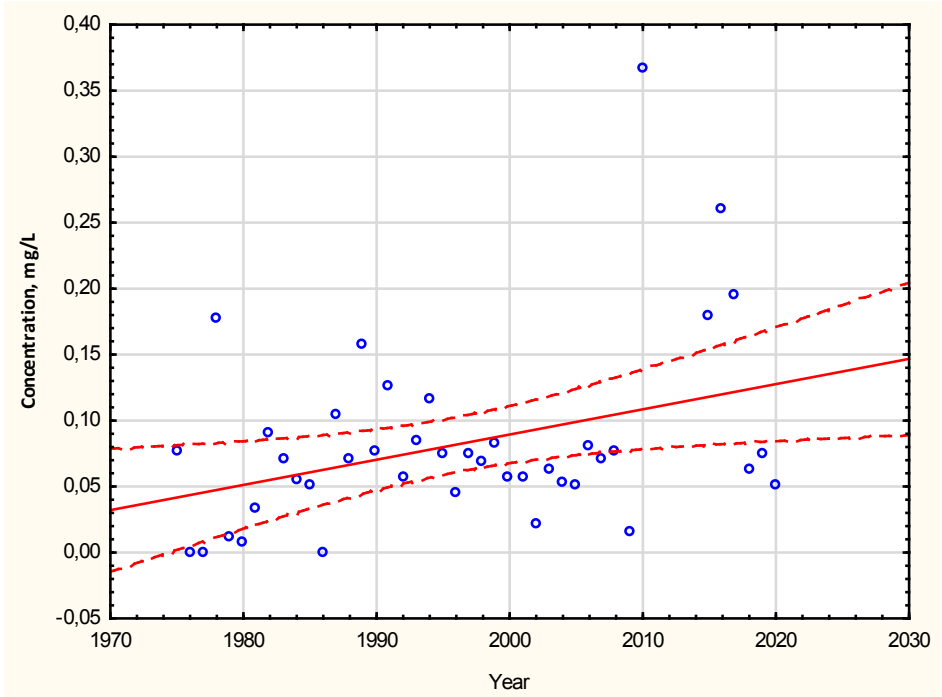

Fig. 8. Manganese content in the Shershnevskoe reservoir water over time.

Tributaries and systemically important Miass River bring compounds of iron and manganese, copper and zinc from urban collecting area of the reservoir and it largely determines high content of heavy metals typical for the region in the Shershenevskoe reservoir water.

Manganese compounds concentrations increase from $0.05 \mathrm{mg} / \mathrm{L}$ to $0.14 \mathrm{mg} / \mathrm{L}$ for the entire period of the reservoir existence. Manganese content in water has increased 2.8 times during just last 15-20 years which points at its accumulation in aquatic environment and characterizes the process of anthropogenic pollution of the reservoir. On the fig. 8 it is shown that manganese ions concentration significantly increases during the research period $(\mathrm{F}=5.817, \mathrm{P}=0.02)$.

For many years the most common reservoir pollutant is copper compounds average annual concentrations of which are constantly 27-70 times higher than fishery standards. The average annual concentrations of copper in the reservoir water were $0.027-0.04 \mathrm{mg} / \mathrm{L}$ for the long-term period until 2000 , reaching a maximum up to $0.07 \mathrm{mg} / \mathrm{L}$ in the $1990 \mathrm{~s}$. 
However, in the last twenty years copper content in the reservoir water has somewhat decreased due to reduction of industrial production in the Chelyabinsk region. On the fig. 9 it is shown that copper concentration in water is statistical significantly decreasing $(\mathrm{F}=17.179, \mathrm{P}=0.0023)$.

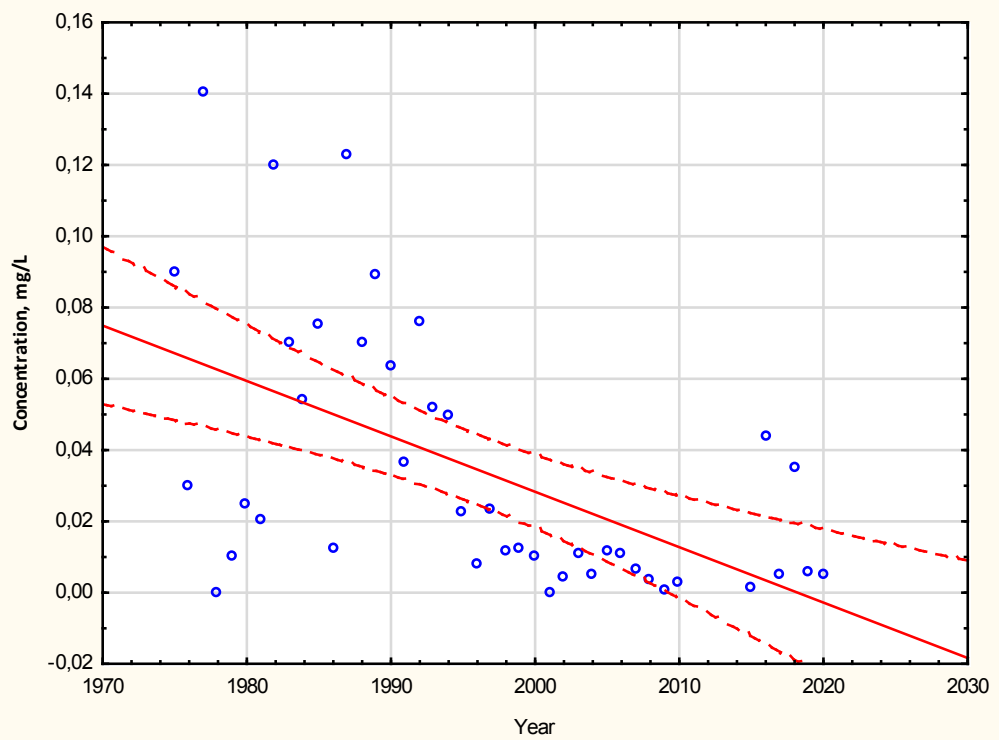

Fig. 9. Copper content in the Shershnevskoe reservoir water over longstanding period.

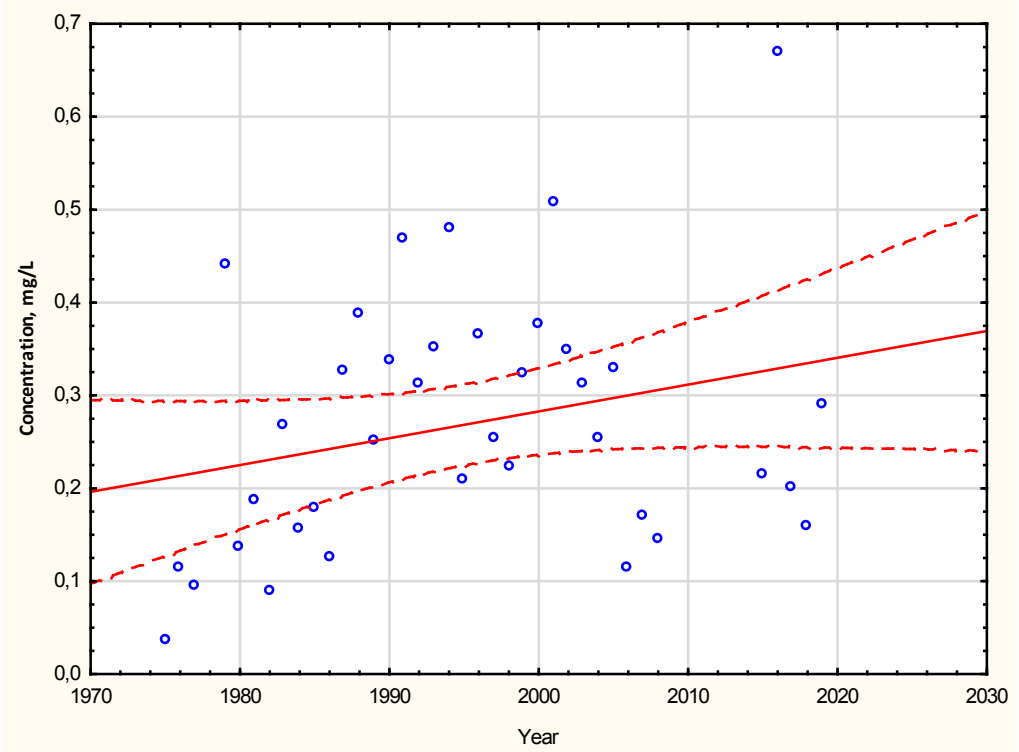

Fig. 10. Iron content in the Shershnevskoe reservoir water over longstanding period.

$\mathrm{Fe}_{\text {total }}$ content in the reservoir water ranges around $0.31 \mathrm{mg} / \mathrm{L}$ in average and increases over the research period from 0.17 to $0.37 \mathrm{mg} / \mathrm{L}$ (fig.10). At the same time, the maximum values of iron in water are recorded in the 1990s. Over the past twenty years the level of iron content in water has been set in the range of $0.31-0.35 \mathrm{mg} / \mathrm{L}$. 


\section{Conclusion}

Evaluation of the water supply source well-being degree of the major industrial center - the city of Chelyabinsk showed that the Shershenevsky reservoir in $100 \%$ of cases corresponds to the main water quality indicators recommended by the SDG 6 and is the "good-quality" water body according to the national standards for maximum permissible concentrations for drinking water use $\left(\mathrm{MPC}_{\text {hygienic }}\right)$ during the entire period of the reservoir existence. In respect of heavy metals contained in water, the "good quality" condition is met in $80 \%$ of cases.

Ecological well-being criterion of the Shershnevskoe reservoir ecosystem is fulfilled for $100 \%$ of cases basically according to the same indicators except for phosphorus. Rated phosphorus content in the period from 2015 to 2020 is observed only for $75 \%$ of cases. When compared with the maximum permissible concentrations for fishery water bodies $\left(\mathrm{MCP}_{\text {fishery }}\right)$ "poor quality" is identified for the entire covered period of time in terms of heavy metal content in water.

Long-term dynamics analysis of the Shershnevskoe reservoir most important water quality indicators showed that for the entire period of the reservoir existence:

- stable neutral-alkaline conditions were established in the reservoir water for growing season with a tendency of alkaline $\mathrm{pH}$ values to increase in the last five years.

- significant decrease of water mineralization, increase of dissolved oxygen content and a strong trend of mineral phosphorus growth are observed, which characterizes strengthening of photosynthetic processes and increase of productivity and anthropogenic eutrophication level of the water body.

- the risk factor for the Shershnevskoe reservoir ecological well-being is heavy metal content, especially iron, manganese and copper.

\section{Acknowledgments}

The research was funded by RFBR and Chelyabinsk Region, project number 20-41-000001.

\section{References}

1. D. Benson, A. Gain, C. Giupponi, Sustainability Science 15, 671-681 (2020) DOI: $10.1007 / \mathrm{s} 11625-019-00733-5$

2. L. Quinlivan, D. Chapman, T. Sullivan, Environmental Monitoring and Assessment 192(4), (2020) DOI:10.1007/s10661-020-8193-6

3. T. Srebotnjak, C. Genevieve, A. Sherbinin, C. Rickwood, Ecological Indicators 17, 108-119 (2012) DOI: 10.1016/j.ecolind.2011.04.023

4. A. Jaffar, et al., Journal of electrical and electronic systems research 17 (2020) DOI: $10.24191 /$ jeesr.v17i1.016

5. S. Poikane, M. Kelly, F. Herrero, J. Pitt, H. Jarvie, U. Claussen, W. Leujak, A. Solheim, H. Teixeira, G. Phillips, Science of the Total Environment 695, 133888 (2019) DOI: 10.1016/j.scitotenv.2019.133888

6. Q. Zhou, et al., Global Ecology and Conservation 22, e00925 (2020) DOI: 10.1016/j.gecco.2020.e00925

7. E. Venitsianov, G. Ageenko, Transactions of IBIW 85(88) (2019) DOI: 10.24411/0320-3557-2019-10001

8. V. Dmitriev, I. Fedorova, A. Birykova, Vestnik of Saint Petersburg University 7, 37-53 (2016) DOI:10.21638/11701/spbu07.2016.204 
9. E. Primak, K. Odinokova, N. Rumyantseva, T. Kaverzneva, S. Efremov, International Scientific Conference EMMFT 2, 408-418 (2019) DOI: 10.1007/978-3-030-574536_37

10. N. Hodorovskaya, L. Deryabina, S. Krayneva, L. Moldanova, K. Chernov, V. Yachmenev, Scientific Medical Bulletin 4(6) (2016) DOI: 10.17117/nm.2016.04 